\section{NOVA TELLVS}

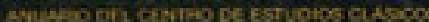

Nova Tellus

ISSN: 0185-3058

novatelu@servidor.unam.mx

Centro de Estudios Clásicos

México

Martínez Lacy, Ricardo

El feudalismo en Bizancio. Corrientes interpretativas modernas

Nova Tellus, vol. 29, núm. 2, 2011, pp. 139-150

Centro de Estudios Clásicos

Distrito Federal, México

Disponible en: http://www.redalyc.org/articulo.oa?id=59122571006

Cómo citar el artículo

- Número completo

- Más información del artículo

- Página de la revista en redalyc.org

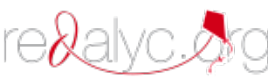

Sistema de Información Científica

Red de Revistas Científicas de América Latina, el Caribe, España y Portugal

Proyecto académico sin fines de lucro, desarrollado bajo la iniciativa de acceso abierto 


\title{
El feudalismo en Bizancio. Corrientes interpretativas modernas
}

\author{
Ricardo MARTínEZ LACY \\ Universidad Nacional Autónoma de México \\ lacy@unam.mx
}

RESUMEN: En este artículo se discute la suerte que ha tenido la aplicación del concepto de feudalismo en la interpretación de la historia bizantina. Los autores incluidos son Vasiliev, Ostrogorsky, Svoronos, Angelov, Kaplan, Haldon, Laiou, Shepard, Jeffreys y Patlagean. Algunos recurren al concepto sin reservas, otros lo rechazan o lo ignoran y últimamente se ha dado un intento de hacer una aplicación más reflexiva.

\section{Feudalism at Byzantium. Modern Interpretative Currents}

ABSTRACT: This article contains a discussion about the fate of the application of the concept of feudalism in the interpretation of Byzantine history. Authors included are Vasiliev, Ostrogorsky, Svoronos, Angelov, Kaplan, Haldon, Laiou, Shepard, Jeffreys and Patlagean. Some resort to it unthinkingly, others reject it or ignore it, and recentely a trend has appeared to take it over more reflectedly.

Palabras Clave: Bizancio, feudalismo, Edad Media. KeYwords: Byzantium, feudalism, Middle Ages.

FECHA DE RECEPCIÓN: 27 de octubre de 2011.

FECHA DE ACEPTACIÓN: 15 de diciembre 2011. 


\title{
El feudalismo en Bizancio. Corrientes interpretativas modernas ${ }^{1}$
}

\author{
Ricardo MARTíNEZ LACY
}

El concepto de feudalismo es un modelo de interpretación. Se le puede definir de muchas maneras, pero aquí se considerará como una relación de señorío y vasallaje mediante la cual el vasallo estaba obligado a rendir servicios a su señor y éste se comprometía a protegerlo.

El trabajo fundamental de Marc Bloch, La Société Féodale, ${ }^{2}$ se ha basado en la manera en que ese modelo ha servido para entender las relaciones económicas, sociales, políticas e ideológicas en el norte de Francia y el suroeste de Alemania. Por ello, se ha señalado que su versión no se aplica con la misma facilidad ni siquiera en el resto de Francia, mientras que, por otra parte, posiciones y prejuicios que vienen desde la Edad Media han tendido a excluir al Imperio bizantino (o Romania, como lo llamaban sus súbditos) de la civilización europea, posición que por cierto tiene su contrapartida entre los habitantes de esas regiones, así como de los países convertidos desde ahí al cristianismo ortodoxo.

A continuación, presentaré un estado de la cuestión y trataré de hacer un balance sobre la capacidad interpretativa de cada posición. Por los azares de la bibliografía y de mis lecturas, me será necesario hacer referencia a obras de muy variado calibre e importancia. Seguiré el orden cronológico de la publicación de la obra.

Me parece conveniente comenzar por La historia del Imperio bizantino de Alexander Vasiliev. ${ }^{3}$ Este autor designa al conjunto de las concesiones de tierra a los soldados como "las tierras de los militares" y los considera feudos

\footnotetext{
${ }^{1}$ Este es el texto de una ponencia presentada en el XIII Congreso de la Sociedad Española de Estudios Clásicos en Logroño en julio de 2011. Fue preparado en ocasión de una estancia sabática transcurrida en la Facultad de Letras de la Universidad de Barcelona por invitación del profesor Alberto Prieto Arciniega. Agradezco al profesor Jordi Cortadella Morral el haberme sugerido correcciones. También agradezco a la DGAPA por concederme una beca PASPA.

${ }^{2}$ M. Bloch, 1968.

${ }^{3}$ A. Vasiliev, 1946.
} 
militares del emperador, a la vez que llama "grandes señores feudales" a los poderosos (dynatoí) (I, pp. 425-426), mientras que considera a Alejo Comneno como "representante de la alta aristocracia terrateniente" (II, p. 125).

Por su parte, Ostrogorsky, tal vez el historiador de Bizancio más influyente del siglo pasado, detecta el inicio de una clase aristocrática bizantina en el siglo VIII, cuando León VI recomendó que las estrategias y las funciones superiores fueran desempeñados por hombres buenos, bien nacidos y ricos (agathós, eugenés, ploúsios), mientras que limitó el derecho preferencial de los vecinos a comprar tierras vacantes (protímesis), lo cual favoreció su enajenación a favor de la nueva nobleza. ${ }^{4}$

El emperador Romano I Lecapeno trató de restaurar el derecho de preferencia en la compra de tierra definiendo con claridad, en una novela de 922, quiénes tenían derecho a comprar o arrendar tierra en poder de los campesinos. Sin embargo, pocos años después, los poderosos aprovecharon un invierno particularmente duro para adquirir tierra de los campesinos y el mismo emperador tuvo que intervenir de nuevo para que los nobles devolvieran la tierra adquirida en términos desventajosos para los vendedores o revendieran la pagada a precio justo. Ostrogorsky duda que la nueva ley surtiera efecto porque los poderosos y los funcionarios eran una sola clase. Además, los propios campesinos trataban de que un patrón los protegiera de los recolectores de impuestos convirtiéndose en dependientes (paroíkoi) de algún aristócrata. El autor sostiene que, en realidad, el Estado defendía su derecho a controlar la pequeña propiedad en contra de la aristocracia terrateniente (pp. 272-276).

Con la muerte de Basilio II (1025), la aristocracia terrateniente se apoderó del Estado y surgió una pugna entre la aristocracia civil, asentada en Constantinopla, y la militar, de las provincias (p. 320). La dinastía de los Comneno personificó la aristocracia militar. Sus emperadores recurrieron a la institución de la prónoia ("previsión”) para nutrir las filas del ejército. La mencionada institución consistía en la concesión de tierra por la que el beneficiario se comprometía a alistarse en el ejército como soldado (stratiôtes) en caso necesario. La superficie de la concesión era tan extensa que implicaba la presencia en ella de campesinos que trabajaran ahí y concurrieran con su señor a la guerra. Éste era, pues, un pequeño señor feudal (pp. 371-372). Los latinos, al tomar Constantinopla en 1204, establecieron un feudalismo de tipo occidental y esto aceleró el proceso interno de feudalización bizantina (p. 424).

${ }^{4}$ G. Ostrogorsky, 1969, p. 255. 
Posteriormente, en palabras de Ostrogorsky (pp. 481-482):

El establecimiento de la dinastía de los Paleólogo en el trono imperial significó una victoria para la más alta nobleza bizantina. El proceso de feudalización revivió y alcanzó su clímax a partir del siglo XIV. Los terratenientes laicos y eclesiásticos extendieron sus haciendas, incrementaron el número de sus parecos, exigieron cada vez más extensos privilegios y con frecuencia se les concedió exención completa de impuestos.

En cuanto a los beneficiarios de la prónoia, se les concedió su derecho a legarlo como herencia. Finalmente, en el siglo XIV, la familia reinante en el restaurado imperio de Constantinopla, que coexistió con otros estados bizantinos, se repartió distintas partes del territorio gobernado; de hecho, ella era la familia más fuerte de las varias de magnates (p. 527).

La visión de Ostrogorsky es consistente. Él describe un proceso de seis siglos (del VII al XIV) mediante el cual surge una aristocracia terrateniente que adquiere dependientes y gana cada vez más poder hasta que logra acaparar el Estado (1025), primero la aristocracia de funcionarios y, luego, la militar (1081). Aunque él no lo diga explícitamente, se puede deducir de su interpretación que el ascenso del feudalismo significó la ruina de Bizancio.

Nicolás Svoronos se ocupó del juramento de fidelidad a los emperadores bizantinos y discernió una continuidad en los usos y costumbres romanos hasta el ascenso de los Comneno, cuando ellos cambiaron la índole de ese juramento. En su propias palabras,

Es a partir de la época de los Comneno que un cambio profundo se opera en el espíritu bizantino: la evolución interna de la sociedad bizantina terminaba por crear relaciones sociales análogas a las del Occidente y el proceso de feudalización en Bizancio se agudizaba cada vez más. La conquista latina, si no fue su causa, por lo menos favoreció esta marcha hacia la feudalización y contribuyó a dar un matiz feudal a la ideología bizantina sobre el estado. En el imperio de Nicea y sobre todo en la época de los Paleólogo este proceso se encuentra en pleno desarrollo. ${ }^{5}$

El principal cambio consistió en que los juramentos se volvieron explícitamente mutuos.

Posteriormente, Svoronos discutió la crisis final de Bizancio en una de las comunicaciones principales del XIII Congreso Internacional de Estudios

\footnotetext{
${ }^{5}$ N. Svoronos, 1973, p. 136.
} 
Bizantinos, cuyas actas fueron publicadas en 1966. El título del discurso fue "Sociedad y organización interior en el Imperio bizantino en el siglo XI: los principales problemas". ${ }^{6}$ Ahí aclara que el primero en plantear la crisis como una pugna entre la nobleza civil y la militar fue originalmente C. Neumann; ${ }^{7}$ él afirma también que la crisis se gestó en el siglo x pero sólo afloró en el siglo XI. Esta consistió en un esfuerzo inicial del Estado por mantener al pequeño campesinado, así como en la resistencia a ello de los potentes. Varios emperadores se esforzaron por defender la existencia de los campesinos libres, pero también los poderosos trataron de "voltear la legislación" (p. 6) con interpretaciones retorcidas de las leyes y francas falsificaciones de documentos legislativos. El poder de la aristocracia provenía de los estrategos de los temas (en griego, thémata), que poseían autoridad a la vez civil y militar, así como tenían a su disposición ejércitos pagados por ellos mismos. Aunque surgió una burguesía de artesanos y comerciantes, favorecida por los emperadores y con acceso al senado, esta no pudo consolidarse. La oposición entre el centralismo del emperador y el anticentralismo de la aristocracia provocó una crisis entre 1025 y 1050 que llevó a la "desorganización completa del sistema defensivo del imperio después de los años sesenta" (p. 10). En consecuencia, el carácter aborigen del ejército se vio afectado.

Dice Svoronos:

A estos factores importantes se agregan la disminución progresiva de la población [...] la crisis de la economía rural que acaba por provocar, sin duda, una crisis económica general y la crisis financiera que fue su resultado (p. 12).

Y concluye:

Esta crisis rebasa los límites de una oposición entre dos castas "nobleza civilnobleza militar". Parece que asistimos a un esfuerzo de transformación de las estructuras estatales con el propósito de sostener el poder sobre bases sociales más grandes, al cual se opone la aristocracia terrateniente representada por su parte más poderosa, la casta militar (p. 17).

Se trata, pues, de una pugna entre el Estado, por una parte, que intenta conservar a los campesinos soldados y contribuyentes, y la aristocracia, por la otra.

\footnotetext{
${ }^{6}$ N. Svoronos, 1973, IX.

${ }^{7}$ C. Neumann, 1984.
} 
En 1974 apareció El feudalismo en Bizancio, de Helène AntoniadesBibicou y otros autores. Me parece que su posición se puede resumir en las palabras de Angelov:

Los estados balcánicos de la edad media siguieron una evolución de tipo feudal. Ciertamente, esta evolución tuvo su carácter propio y sus rasgos específicos, determinados por las condiciones históricas concretas [...] Pero, a la vez, la documentación abundante de la que disponemos revela una semejanza indudable entre el este y el oeste... ${ }^{8}$

Michel Kaplan publicó en 1992 un libro sobre los hombres y la tierra en Bizancio del siglo VI al XI, ${ }^{9}$ obra donde admite que los límites cronológicos son un poco arbitrarios y el más bajo excluye el periodo en que la aristocracia, en términos de Ostrogorsky, se apodera del Estado, lo cual parece ser la característica más notoria del desarrollo del feudalismo bizantino. Divide además su periodo de estudio en dos etapas. La primera, del siglo vi al VIII, fue la era de los campesinos independientes, mientras que la segunda, de los siglos IX al XI, fue la del resurgimiento de los poderosos.

Sobre la primera época, el capítulo más esclarecedor parece ser el VI, "La sociedad aldeana" (pp. 219-280), en el que presenta una división de la sociedad en términos geométricos, desde los grandes propietarios, pasando por la élite, los soldados campesinos ("en el corazón de la sociedad de la aldea", p. 231), los pequeños campesinos independientes y los marginales, hasta llegar a los no agricultores. Resta importancia a los factores de estatus jurídico y considera que lo decisivo fueron los ingresos, de tal manera que los parecos más ricos acaban descritos como un grupo que vivía en un nivel material parecido al de los pequeños propietarios.

En ese mismo capítulo, Kaplan plantea que en una época tan temprana como el siglo vi existían los potentes, que Justiniano trató infructuosamente de frenar (pp. 177-180). Ya para entonces ejercían el patronazgo, "pero la autoridad sobre los hombres sólo les interesa en la medida en que les permite asegurar la permanencia de la renta, mediante la fijación a la tierra del colono y más tarde del pareco. Si no se comprende correctamente esta realidad, se puede uno inmiscuir en controversias sin fin sobre el 'feudalismo' bizantino o su ausencia” (p. 181).

${ }^{8}$ D. Angelov, 1974, p. 103.

${ }^{9}$ M. Kaplan, 1992. 
Esto sugiere que para Kaplan lo decisivo en el feudalismo son los vínculos de vasallaje, pero él mismo no lo deja claro.

Sea de esto lo que fuere, sostiene Kaplan que, a principios del siglo VII, florecían tanto los pequeños campesinos independientes como los poderosos, porque había espacio para ambas clases. En la misma página (n. 283) expresa su aprobación por la opinión de John Haldon ${ }^{10}$ de que no puede ubicarse a Bizancio "en tal o cual modo de producción", sin tomar en cuenta que se está refiriendo a una categoría abstracta, pues lo que se da en la historia son las formaciones económico-sociales.

En el capítulo más largo, intitulado "La renovación de la gran propiedad: Ricos y poderosos frente a los débiles y pobres" (pp. 281-373), Kaplan afirma que, para el siglo IX, la aristocracia había logrado asentar su supremacía en la sociedad bizantina; enumera los pocos datos transmitidos sobre el monto de su riqueza, consistente sobre todo en tierra y ganado; describe la manera en que era administrada, y manifiesta su acuerdo con Svoronós en el sentido de que la mayor parte de la tierra era cultivada por parecos. Había desde luego otro tipo de pequeños campesinos y de contratos: la enfiteusis y el arrendamiento.

En el capítulo sucesivo analiza la legislación promulgada por los emperadores de la dinastía macedonia entre 922 y 996 con el objeto de garantizar la pervivencia del pequeño campesinado independiente, pero constata su ineficacia, pues a fines del siglo x la mayoría de los labradores eran parecos.

En el capítulo XI, Kaplan reitera la idea de que entre los siglos VI y IX hubo un auge de los pequeños campesinos, que Bizancio sufrió una crisis de ocupación de la tierra en el siglo x y que la recuperación a partir del siglo sucesivo dependió de la iniciativa de la aristocracia laica y eclesiástica, "lo que simboliza el triunfo de los Comneno" (p. 540).

En el capítulo XII (“Una economía bloqueada por la autarquía”, pp. 523-573), Kaplan concluye, diciendo, que la dinastía de los Comneno impidió el desarrollo de la burguesía al expulsarla del senado, y sostiene que el ascenso al poder de esa familia constituye un verdadero cambio de régimen. En primer lugar, porque el beneficio de las gratificaciones del Estado se reserva crecientemente a la familia imperial y a sus clanes aliados. El vínculo personal o familiar con el emperador y la dinastía, antes marginal, sustituye a la noción de servicio al Estado: se remunera menos la función ejercida en interés del Estado que la fidelidad a la familia reinante (p. 571).

\footnotetext{
${ }^{10}$ J. Haldon, 1985, pp. 75-112.
} 
El autor plantea otra idea importante: mientras que en Europa occidental los señores presionaron a sus súbditos para que produjeran más, en Bizancio no existía la posibilidad de inversiones productivas.

Aunque la conclusión general (pp. 575-581) es más bien descriptiva, sin embargo, Kaplan sostiene que la fiscalización empezó por estar a cargo de los curiales y terminó controlada por los "agricultores-explotadores", lo cual fue "un cambio de régimen" (p. 580). Asimismo, reafirma que "Bizancio no conoció el señorío rural" (p. 581).

John Haldon ha escrito muchos libros y artículos sobre el Imperio bizantino. Aquí me concentraré en su libro El Estado y el modo de producción tributario, que apareció en 1993. ${ }^{11}$ Según el tercer volumen de El capital, el modo de producción tributario consiste en la extracción de plusvalía por medio de impuestos o rentas. ${ }^{12}$ Esta es una interpretación de Samir Amin, que en El desarrollo desigual reinterpretó la idea del modo de producción asiático de Marx..$^{13}$ Haldon propone que casi todas las economías precapitalistas fueron tributarias, entre ellas el feudalismo, por lo que habla de una economía feudal/tributaria. En consecuencia, considera los cambios en la economía bizantina como superestructurales y sostiene que la toma del poder por la aristocracia representó un cambio en la esfera de la distribución y no en el de la producción. Los campesinos en lugar de pagar impuestos al Estado los pagaban, en forma de pactos, supongo yo, a sus patrones. ${ }^{14}$

Ver casi todos los modos de producción precapitalistas como despóticotributarios borra las diferencias que había visto el propio Marx en los Grundrisse (Formas que preceden a la producción capitalista ${ }^{15}$ ), que concebía el modo de producción feudal como evidentemente distinto del asiático. Postular que los impuestos y las rentas son la forma de extracción de plusvalía de ese modo de producción es atribuirle una extensión tan grande que puede anular también la distinción entre todos los modos de producción. Negar que la toma del poder de los Comneno represente la asunción al poder de la aristocracia es desestimar la importancia de una revolución.

\footnotetext{
${ }^{11}$ J. Haldon, 1993.

${ }^{12}$ Haldon cita una traducción inglesa, en la p. 794.

${ }^{13}$ S. Amin, 1977; hay una traducción al español: El desarrollo desigual: ensayo sobre las formaciones sociales del capitalismo periférico (Barcelona, Libros de confrontación, 1974).

${ }^{14}$ J. Haldon, op. cit., pp. 109-139.

${ }^{15}$ K. Marx, 1971.
} 
El centro de estudios Dumbarton Oaks es la institución estadounidense más importante en los estudios de Bizancio. En 2002, bajo la edición de Angeliki Laiou, publicó una monumental historia económica de Bizancio de más de mil páginas. ${ }^{16}$ Sin duda se trata de la recopilación de datos más larga que se ha hecho hasta ahora, pero evita usar términos históricos, como feudalismo, precisamente, $\mathrm{y}$, al final, cuando Laiou propone un modelo para entender la economía bizantina, divide la producción en dos sectores: la monetizada y la no monetizada (p. 1154), como si sólo hubiera podido haber una forma de cada una. Además, al exponer las condiciones de arrendamiento de los parecos, lo hace como si se tratara de un obrero capitalista impulsado sólo por el mercado y no hubiera constricciones políticas entre los contratantes. ${ }^{17}$

Jonathan Shepard fue el editor de una historia de Bizancio publicada por la Universidad de Cambridge.$^{18}$ Esta obra presenta un capítulo de veintiocho páginas dedicado a la economía ${ }^{19}$ que contiene una exposición muy descriptiva, y sólo al final el autor empieza a explicar los posibles modelos de interpretación, como si la descripción no fuera también un modelo. Las posibilidades que se barajan es si interpretar la economía bizantina como feudal o de mercado. Al final, Whittow afirma paradójicamente que ambos modelos tienen méritos, pero faltan datos para decidirse por uno de los dos (p. 491). Posición eminentemente empírica.

En otro capítulo, ${ }^{20}$ se define sin ambages la índole del Imperio latino de Constantinopla y de los estado francos que surgieron en Romania a raíz de la cuarta cruzada (1204) como claramente feudales porque los cruzados importaron el feudalismo de Europa occidental.

Esto sugiere que los autores de esta obra tienen una concepción purista y restrictiva del feudalismo.

Es un caso aún más extremo el del manual de Oxford de estudios bizantinos. ${ }^{21}$ Ahí, en el capítulo sobre la economía (de Alan Harvey, pp. 631-641) y en el capítulo sobre la aristocracia y la burocracia (de JeanClaude Cheynet, pp. 518-526) no se encuentran más que descripciones, y no se mencionan a los parecos, los pactos, ni se explican las relaciones

\footnotetext{
${ }^{16}$ A. E. Laiou, 2002.

${ }^{17}$ Pp. 302-305. Los tres volúmenes tienen una numeración continua.

${ }^{18}$ J. Shepard, 2008.

${ }^{19}$ M. Whittow, en Shepard, op. cit., pp. 465-493.

${ }^{20}$ D. Jacoby, en Shepard, op. cit., pp. 759-779.

${ }^{21}$ E. Jeffreys, 2008.
} 
sociales (de producción) que permitían el sostenimiento de los poderosos.

Évelyne Patlagean publicó en 2007 Un medioevo griego. Bizancio del siglo IX al XIV. ${ }^{22}$ Ella plantea una concepción más flexible del feudalismo que la de Bloch, para aplicarla a partes como Italia, Cataluña y Bizancio. Pasa revista a todos los conceptos que manejó el genial autor francés y encuentra que el don y la prónoia eran instituciones plenamente feudales, y hace la observación de que la Europa occidental y la oriental siguieron procesos opuestos, ya que en aquélla primero cayó el Imperio romano y luego se empezaron a construir estados que tendían a reforzarse (como Francia e Inglaterra), mientras que en Bizancio, Roma no cayó, pero el ascenso de la aristocracia coincidió con la destrucción del Estado hasta su conquista por los turcos.

Al parecer, a principios del siglo XX no había empacho en aplicar la idea del feudalismo al Imperio bizantino, y sólo en el siglo XXI ha surgido una reticencia al respecto, que ha recibido una respuesta más consciente.

No hay visos de que el debate vaya a concluir y si, como temía Kaplan, resulta infinito, mejor. Sin embargo, pueden discernirse dos grandes tendencias: una, que se puede llamar empírica y que se resiste, por distintas razones, a aplicar concepciones históricas como el feudalismo, y la otra, que se puede considerar interpretativa y no teme el uso de esas categorías, precisamente. Para la primera, Europa occidental y oriental son totalmente distintas; para la segunda, son perfectamente comparables.

\section{BIBLIOGRAFÍA}

Амім, Samir, Imperialism and Unequal Development, New York / London, 1977.

Angelov, D., "Le Féodalisme dans les Balkans du XIIIe au Xve siècles", en Helène Antoniades-Bibicou et al., Le Féodalisme à Byzance. Problèmes du mode de production de l'empire byzantin. Recherches internationales à la lumière du marxis$m e$, Paris, Les éditions de la Nouvelle Critique, 1974, pp. 90-106.

Bloch, M., La Société Féodale, 5a ed., Paris, Albin Michel, 1968.

Haldon, J., "Some Considerations on Byzantine Society and Economy in the Seventh century", Byzantinische Forschungen, 10, 1985, pp. 75-112.

_, The State and the Tributary Mode of Production, London, Verso, 1993.

JACOBY, David, "The Latin Empire of Constantinople and the Frankish States", en J. Shepard (ed.), The Cambridge History of the Byzantine Empire c. 500-1492,

\footnotetext{
${ }^{22}$ É. Patlagean, 2007.
} 
Cambridge, Cambridge University Press, 2008, pp. 759-779.

JEFFREYs, Elizabeth et al., The Oxford Handbook of Byzantine Studies, Oxford, Oxford University Press, 2008.

Kaplan, M., Les Hommes et la terre à Byzance du vie au XIe siècle. Propriété et exploitation du sol, París, Publications de la Sorbonne, 1992.

LaIou, Angeliki E. (ed.), The Economic History of Byzantium, 3 vols., Washington, Dumbarton Oaks Research Library and Collection, 2002.

MARX, K., Formas que preceden a la producción capitalista, Córdoba, Pasado y Presente, 1971.

Neumann, Carl, Die Weltstellung des byzantinischen Reiches vor der Kreuzzügen, Leipzig, Verlag von Dunker \& Humblot, 1894.

OstrogORSKY, George, History of the Byzantine State, traducción al inglés de J. Hussey, New Brunswick, Rutgers University Press, 1969.

Patlagean, Évelyne, Un Moyen Âge Grec. Byzance Ixe-Xve siècle, Paris, Albin Michel, 2007 (L'Évolution de l'humanité).

SHEPARD, J. (ed.), The Cambridge History of the Byzantine Empire c. 500-1492, Cambridge, University Press, 2008.

Svoronos, Nicolás, Études sur l'organisation intérieure, la société et l'économie de l'Empire Byzantin, prefacio de P. Lemerle, London, Variorum Reprints, 1973.

_, "Société et organisation intérieure dans l'empire byzantin au XI ${ }^{\mathrm{e}}$ siècle: les principaux problèmes", in Proceedings of the XIII ${ }^{\text {th }}$ International Congress of Byzantine Studies, Oxford, 1966, pp. 12-17. Reprinted in N. Svoronos, 1973, no. IX.

VAsiliev, Alexander A., Historia del Imperio Bizantino, 2 vols., traducción de J. G. de Luaces, Barcelona, Iberia, 1946.

WhitTow, Mark, “The Middle Byzantine Economy”, en J. Shepard (ed.), The Cambridge History of the Byzantine Empire c. 500-1492, Cambridge, Cambridge University Press, 2008, pp. 465-493. 